\title{
Medios de comunicación, marcos de referencia y construcción de identidades
}

\author{
Salomé Sola Morales \\ (Universidad Autónoma de Barcelona, Universidad de Sevilla, \\ Universidad de Santiago de Chile)
}

Recibido: $17 / 12 / 2013$

Aprobado: 11/6/2014

\begin{abstract}
Resumen: Este ensayo teórico aborda la importancia de los marcos de referencia en la construcción de las identidades. Además, subraya el papel que los medios de comunicación tienen en la configuración de dichos marcos. Primero, se realiza una revisión de los aportes y limitaciones de la teoría de la identidad social. Segundo, se subrayan las principales contribuciones de los enfoques fenomenológicos. Tercero, se destacan los aportes de Erving Goffman y se vindica la superación del esencialismo, tan arraigado en las clásicas teorías de la identidad.
\end{abstract}

Palabras clave: marcos de referencia / identidad / construcción de la realidad / medios de comunicación

\section{Media, frameworks and identity construction}

Summary: This theoretical essay discusses the importance of frameworks in the construction of identities. Also emphasizes the role the media play in shaping such frameworks. First, a review on the contributions and limitations of the theory of social identity is performed. Second, the main contributions of phenomenological approaches are highlighted. Third, we highlight the contributions of Erving Goffman and we vindicate the overcoming of essentialism, a trend rooted in the classical theories of identity.

Key words: frameworks / identity / construction of reality / media 


\section{Introducción: la búsqueda de sentidos}

L a inestable situación del hombre en el mundo, como ser jamás fijado completamente, hace que el sentido - y su búsqueda- se convierta en una pregunta fundacional de existencia. La persistente lucha y amenaza del caos sobre el cosmos y las ansias por superar la contingencia son características humanas insuperables. De hecho, aunque el anthropos intente unificar sus fragmentos de vida, acotar el espacio, controlar el tiempo o luchar contra las desavenencias naturales, su condición cultural y simbólica le hace estar permanentemente errando y buscando respuestas a los grandes interrogantes.

Como bien han expresado Reinhart Koselleck y Hans-Georg Gadamer (1997), la fuerza humana se caracteriza por «resistir a todos los desafíos que la realidad nos impone mediante el sinsentido (unsinn), la demencia (wahnsinn) y la desconcertante absurdidad (sinnlosigheit), y hacerlo perseverando en una búsqueda incansable de lo comprensible y el sentido» (Gadamer, 1997, p. 100). Aunque como dicen los sociólogos del conocimiento Alfred Schütz y Thomas Luckmann: «Nuestro primer impulso es tomar como inmediatamente real todo aquello a lo que nos referimos, en la medida en que no sea contradicho. Sin embargo, debe haber varios - probablemente infinitosórdenes diferentes de realidad que, en un momento dado, tienen un espe- cial estilo de ser» (2001, p. 42). Por ello, mientras prestamos atención a uno de esos mundos, sentimos que es real en cierta medida, pero tan pronto como se le retira la atención, el mundo desaparece como realidad. Así planteado, en la medida en que la realidad carece de un horizonte de sentido, deja de ser real. De modo que el sentido más que singular habría de ser entendido de manera plural, puesto que está sometido a los diferentes espacios y tiempos, y no solo a los diferentes individuos, sino también a los diferentes sistemas socioculturales en los cuales emerge. Y aunque la significación del mundo no esté dada y tan solo haya múltiples significaciones que se construyen en el fluir incesante de pluralidades de intereses humanos, el ser, mediante la interacción comunicativa y el reconocimiento intersubjetivo, busca comprender su rol en el cosmos. Por lo tanto, analizar la dimensión experiencial, las estructuras y los procesos de comprensión, que constituyen el contexto sociocultural y mediático, donde el yo individual y social se inserta, es crucial. Y aquí es donde los marcos de referencia emergen como una herramienta teórica clave para abordar cuestiones empíricas tales como la configuración de identidades, sean estas individuales o grupales. Pero, sobre todo, vale la pena preguntarse por el papel de los medios de comunicación en tanto refiguran y vehiculan estos modelos y pautas de comportamiento psicosocial. En lo sucesivo revisaremos algunas teo- 
rías, que si bien podrían considerarse antiguas, a nuestro juicio, se revisten de un interés crucial para desentrañar el rol de los medios de comunicación en la construcción de las identidades $y$, dicho sea de paso, trataremos de superar algunas de las limitaciones que plantean.

\section{De lo individual a lo social: la teoría de la identidad social}

Quizás fuese William James el psicólogo que primero introdujo el concepto de yo social, entendido en íntima relación con la experiencia, la actividad y, sobre todo, el medio (1989). No es de extrañar, por tanto, que el pragmatismo de James se convirtiese, años más tarde, en la base del pensamiento de conocidos psicólogos sociales como James Mark Baldwin, George Herbert Mead o Herbert Blumer. El conjunto social, donde el homo socius ${ }^{1}$ se inserta y constituye su experiencia, se convierte así en el eje vertebrador de las aportaciones de la mayoría de los psicólogos sociales y los fenomenólogos. En este sentido, la teoría de la identidad social, propuesta inicialmente por el psicólogo social Henri Tajfel, se encuentra muy influida por esta concepción y nos resulta de gran relevancia para comprender el alcance de los marcos de referencia en la construcción de las identidades sociales. Tal y como ha expresado el investigador:

Las relaciones humanas siempre ocurren en un ambiente social organizado - en una familia, en un grupo, en una comunidad, en una nación- que ha desarrollado técnicas, categorías, reglas y valores que son relevantes para la interacción humana. Por lo tanto, la comprensión de los acontecimientos psicológicos que tienen lugar en las interacciones humanas requiere la comprensión de la influencia recíproca de esos acontecimientos con el contexto social en el cual ocurren (Tajfel, 1984, pp. 2-3).

El carácter innovador de la propuesta de Tajfel radica en el valor que otorga a lo social, abandonando cualquier clase de psicologismo individualista. Así, el yo es fruto de las relaciones del sujeto con el entorno y se encuentra muy influido por su pertenencia grupal. El investigador define la identidad social como la conciencia que tienen los individuos de pertenecer a un grupo social. Es importante señalar que existe una cierta uniformidad dentro de este, que hace sentir a sus miembros iguales o similares, tal y como han subrayado Michael A. Hogg y Elizabeth A. Hardie (1992). Ahora bien, es preciso puntualizar que esta homogeneidad grupal es instaurada

1 Véanse las importantes formulaciones sobre la socialidad del hombre aportadas por el sociólogo francés E. Durkheim en Las formas elementales de la vida religiosa, 1968. 
no solo por las instituciones clásicas (familia, Estado, escuela...), sino también, y cada vez más, por los medios de comunicación en tanto estructura de acogida o institución socializadora fundamental (Duch, 2010). Los medios de comunicación funcionan como una «comunidad interpretativa» (Schrøder, 1994) que facilita a los sujetos adoptar un lenguaje y las pautas de comportamiento social de un colectivo. Esto puede verse claramente hoy en día en el desarrollo de comunidades virtuales que adoptan lenguajes propios en función del mismo grupo, edad o temática compartida. Estamos pensando, por ejemplo, en las comunidades virtuales Pro-Ana o Pro-Mía, que promueven y apoyan enfermedades alimentarias tales como la anorexia o la bulimia, y para ello utilizan un lenguaje propio incomprensible para aquellos ajenos al grupo.

Por eso, además de existir grupos o categorías de pertenencia, en los que un sujeto dado nace o se inserta a lo largo de su trayectoria sociocultural, y que, por supuesto, influencian a los individuos, también existen los llamados grupos de referencia (Merton, 1970; Sherif, 1964) con los que el individuo se relaciona o aspira a relacionarse psicológicamente. Aquí podríamos mencionar, por ejemplo, grupos de estatus superior con los que ciertos individuos se identifican. Dado que los medios muchas veces no ofrecen imágenes acerca de colectivos marginales o menos empoderados, los sujetos terminan identificándose, adquirien- do productos similares o visionando series o películas acerca de colectivos muy diferentes de los propios. La familia real española, por ejemplo, se ha convertido en uno de los productos mediáticos preferidos de colectivos con pocos recursos, que toman a estos individuos como modelos de referencia, cuyas pautas de comportamiento social (vestimenta, jerga, conducta pública, etc.) son aprendidas a través de los discursos mediáticos (revistas, noticieros, blogs, entre otros). Estos grupos de referencia, como ha expresado el psicólogo social Henry Clay Lindgren, «pueden servir como fuente de actitudes y valores que son imitados y constituyen una base para el aprendizaje ulterior» (1979, p. 91). En este caso, los individuos no tienen por qué ser miembros para que los grupos de referencia los afecten. Esto se debe a que estos grupos no tienen que estar necesariamente asociados a las clásicas definiciones esencialistas, tales como el origen o el linaje y se vinculan más a las proyecciones y deseos (Sola, 2012). Precisamente, aquí los individuos pueden desarrollar una suerte de proyecciones llamadas por Cecilia von Feilitzen y Olga Linne (1975) wishful identifications o, lo que es lo mismo, identificaciones desiderativas. $\mathrm{Y}$ estas últimas podrían estar relacionadas con los grupos de referencia a los que los individuos aspiran o desean pertenecer (Sola, 2013).

A este respecto, los nuevos medios de comunicación on-line propician formas de adhesión múltiples y re- 
lativamente débiles, donde el sujeto puede transitar, modificar o cambiar de grupo cuando y donde quiera, sin preocuparse por las relaciones reales o por el colectivo mismo, ya que está muy centrado en la propia subjetividad (Dubar, 2002). De modo que, más que categorías de pertenencia, el sujeto configura grupos de referencia con los que se relaciona o aspira a relacionarse psicológicamente. Estas comunidades de guardarropa, si utilizamos la acepción de Bauman (2003), o identidades sociales puntuales, en palabras de Íñiguez (2002), se caracterizan por la inmediatez y por la liquidez. Y más que ser adquiridas poco a poco, son adoptadas eventual y fugazmente en función de las circunstancias y las necesidades psicosociales.

Además, en el espacio virtual, los sujetos configuran identificaciones posibles o ideales que no tienen por qué ser reales o estar asociadas a roles o papeles sociales. Y por ello, el sentimiento de pertenencia no tiene que estar relacionado con las categorías heredadas por el linaje o adquiridas por la experiencia social. De hecho, estas formas de identificación pueden ser imaginadas o desiderativas y se encuentran muy relacionadas con las proyecciones o los deseos. La clásica pregunta «¿quién soy?» sería respondida aquí en términos desiderativos o imaginarios. Ahora bien, más allá de estas categorías de referencia con las que el sujeto se identifica con base en proyecciones o deseos, existen nuevos sentimientos de pertenencia asociados al consumo mediático o a la participación en entornos virtuales (Sola, 2012). Estas nuevas categorías de adherencia son flexibles y carecen de objetivos, motivaciones sociales o incluso responsabilidades.

No cabe duda, por consiguiente, de que tanto los grupos de pertenencia como los de referencia sirven al individuo como modelos para estructurar el medio y darle significaciones diversas. Así planteado, las adquisiciones grupales que realizan los individuos evidencian que en una sociedad compleja ningún grupo social vive aislado respecto a otros, ya que no somos seres extraculturales. De modo que «los procesos que subyacen a las autocomparaciones que cada grupo hace con otros grupos son cruciales para determinar la comprensión que de cada grupo tienen sus miembros» (Tajfel, 1984, p. 193). La diferenciación entre grupos se basa, por tanto, en la identificación que los sujetos realizan con su endogrupo y las comparaciones y evaluaciones efectuadas con relación al exogrupo. Ahora bien, nuestra propuesta radica en el hecho de que estas comparaciones (generalmente duales) se encuentran instituidas por los medios de comunicación, que se han convertido en una de las estructuras de acogida fundamentales de los individuos y los grupos (Duch, 2010).

Si bien la teoría de Tajfel podría aportar claves para una definición de la identidad social, que en sus pa- 
labras es «aquella parte del autoconcepto de un individuo que deriva del conocimiento de su pertenencia a un grupo (o grupos) social junto con el significado valorativo y emocional asociado a dicha pertenencia» (Tajfel, 1984, p. 292), para nosotros la pregunta debería ser cómo se configuran estas identidades, que además de ser socialmente compartidas son ante todo narrativas (Bamberg, 2011; Bühler \& Habermacher, 1988; Kerby, 1991; Pizzinato, 2008; Ricoeur, 1996, 1999, 2007; Somers, 1994; Sola Morales, 2012, 2013; Taylor, 1996; Thiebaut, 1989) y, en definitiva, construidas en un intercambio dialógico. Y, sobre todo, sobre la base de qué referentes simbólico-culturales estas son definidas.

Es cierto que el enfoque propuesto por Tajfel aporta elementos interesantes, ya que es eminentemente sociocognitivo, pero no podemos olvidar el rol de la cultura y los medios de comunicación en la configuración de este autoconcepto ni tampoco el de la propia psique, lugar en el que el individuo y el colectivo crean muchas de sus aspiraciones, deseos o proyecciones imaginadas (Anderson, 1993). De hecho, la identidad social, así vista, sería más bien un sistema de ordenación que ayuda a crear y definir el puesto del individuo en la sociedad. Precisamente, si revisamos los planteamientos de la teoría de la identidad social, el self se forma mediante procesos de autocategorización que permiten a los individuos conocer a qué grupo social o categorías sociales pertenecen (Tur- ner, 1990; Hogg \& Abrams, 1988) y realizar comparaciones sociales respecto a los demás. Pero ¿sobre la base de qué se realizan dichas comparaciones? No olvidemos que desde este enfoque, que a nuestro juicio es un tanto limitado, las categorías están en la sociedad en su propia estructura y preceden a los individuos. De modo que son los individuos los que van configurando un conjunto de diversas categorías sociales en el curso de sus vidas, que les permiten conformar su propio autoconcepto (Stets \& Burke, 2000, p. 225). Ahora bien, esta propuesta, que da a las categorías sociales una preeminencia estructural, olvida que estas son continuamente refiguradas en función de su contexto sociocultural, pero también en función de las necesidades psicológicas de los individuos y los grupos. Por ello, los productos de la cultura (desde la literatura hasta los blogs) ejercen un poder sustancial en la configuración de modelos de referencia y pautas de comportamiento psicosocial.

Las aportaciones de otros psicólogos sociales como Dominic Abrams y Michael A. Hogg (1990), John C. Turner y Rina S. Onorato (1999), Steve D. Reicher (1989), Rupert Brown (2000) o las de Anastasio Ovejero (1997) permiten ampliar la capacidad interpretativa de las herramientas conceptuales expresadas por Tajfel, que si bien son interesantes en algunos aspectos, pueden resultar limitadas, ya que se centran demasiado en las categorías sociales, más que en el propio proceso de cons- 
trucción o en la necesaria movilidad comunicativa de las mismas. Precisamente, lo interesante sería saber cuáles son los procesos por los que los sujetos construyen su propio autoconcepto y sobre la base de qué mecanismos este va adoptando formas diversas a lo largo de la trayectoria vital. Tal y como ha expresado Lupicinio Íñiguez (2002), la descripción de las identidades sociales puntuales, que se generarían espontáneamente en situaciones de comportamiento colectivo, arroja nueva luz y desencializa la noción de identidad social haciéndola contextualmente dependiente. Aquí sería donde se manifestaría la conexión necesaria entre identidad social y marcos de referencia. Justamente, los marcos - entendidos como herramienta conceptualnos permitirán «desencializar» la noción de identidad vinculándola a un contexto en constante cambio y transformación $\mathrm{y}$, sobre todo, a un marco de referencia cultural y mediático desde el cual podamos interpretarla ideológicamente.

\section{El mundo de la vida cotidiana: los aportes de la fenomenología}

El concepto husserliano mundo de vida, entendido como horizonte universal y categoría apriorística, constituye la piedra angular de los aportes de la fenomenología y nos permite concebir la importancia de este contexto que venimos mencionando. Así podemos considerar que los medios de comu- nicación, en cuanto discursos culturales, políticos y económicos, podrían formar parte de este horizonte contextual. Para Husserl (1991, p. 146), el mundo de vida es el constante suelo de validez, el marco universal o la estructura general, en la que fluyen todos nuestros fines, metas, realizaciones, actividades y capacidades operativas, o, lo que es lo mismo, el lugar donde se desenvuelve nuestra experiencia real. En este sentido, entendemos el mundo de vida aquí como el de la significación, independientemente de las limitaciones (Blumenberg, 2013) que este concepto de moda en el pensamiento filosófico desde los años veinte pueda tener.

Algunos años más tarde que Husserl y también desde la fenomenología, Alfred Schütz reinterpretará este concepto y le dará el nombre de mundo del sentido común, mundo de la vida o mundo de la vida cotidiana (lebenswelt), otorgando así mayor énfasis a la intersubjetividad y a la experiencia. Más allá de la definición de este complejo y también ambiguo concepto, lo que nos preocupa aquí es de dónde surgen estos significados compartidos y este sentido común. Es obvio que desde las instituciones hegemónicas, pero, sobre todo, desde los medios de comunicación. Este mundo del que hablan Husserl y Schütz no es un mundo privado o propio del individuo aislado, sino que se trata de «un mundo común y comunicativo» (Schütz \& Luckmann, 2001, p. 25) compartido por todos nosotros, que debe ser interpretado en la experiencia, ya que puede ser transfor- 
mado y modificado por los individuos en la misma. De ahí que sea tan relevante estudiar los procesos mediante los cuales los marcos o esquemas de comprensión configuran las creencias compartidas y los imaginarios colectivos que dan lugar a la creación y recreación de identidades sociales y el papel que los medios tienen en este proceso.

El hombre y la mujer utilizan acervos de conocimiento a mano, que se encuentran integrados por tipificaciones del mundo del sentido común, para comprender y controlar la experiencia circundante. Esta idea ha sido retomada por Peter Berger y Thomas Luckmann (2008), ambos discípulos de Schütz, que consideran que la realidad de la vida cotidiana contiene esquemas tipificadores en cuyos términos los otros son aprehendidos. Como han expresado ambos, estos encuentros son típicos en un sentido doble: «Yo aprehendo al otro como tipo y ambos interactuamos en una situación que de por sí es típica» (Berger \& Luckmann, 2008, p. 47). Pero, además de típico, este es un mundo de cultura, aprehendido como un horizonte abierto de significaciones, en palabras de Schütz, ya que, desde el principio, «el mundo de la vida cotidiana es un universo de significación para nosotros, vale decir una textura de sentido que debemos interpretar para orientarnos y conducirnos en él» (Schütz, 2003, p. 41).

Bajo esta premisa, se evidencia el postulado hermenéutico de la inter- pretación subjetiva de las ciencias sociales propuesto por Schütz, del que se deriva que la comprensión -ontológica y metodológica- de cualquier objeto cultural siempre estará determinada por la actividad humana en la cual se origina y desarrolla. $Y$, a su vez, por los marcos desde los cuales esta es interpretada y comprendida por los humanos. Por este motivo, reivindicamos el estudio de los marcos como una herramienta comprensiva fundamental. Más aún, cuando lo que se trata de estudiar es el rol de los medios de comunicación en la configuración de las identidades. Dado que el universo de significación hoy en día no se halla implícito, ya que hay una carencia de metadiscursos o metarrelatos, este debe hacerse explícito en función de las pequeñas historias que constituyen la cotidianeidad y que los medios se encargan de vehicular.

Sin embargo, no podemos olvidar, como exponen Berger y Luckmann en su archiconocida La construcción social de la realidad, que aunque estos objetos culturales - entre los que podríamos incluir los relatos mediáticos- proclamen las intenciones subjetivas de nuestros semejantes, a veces resulta difícil saber con seguridad qué revelan exactamente (Berger \& Luckmann, 2008, p. 51). Y es que el sentido, tal y como expresan Schütz y Luckmann en Las estructuras del mundo de la vida, no es una cualidad de ciertas vivencias que emergen nítidamente en el flujo de conciencia, es decir, de las objetivi- 
dades constituidas dentro de esta, sino que es, más bien, el resultado de una explicación de vivencias pasadas «que son captadas reflexivamente desde un ahora actual y desde un esquema de referencia actualmente válido» (Schütz \& Luckmann, 2001, p. 36). Este esquema o marco común de interpretación es fundamentalmente la realidad primordial, o paramount reality — como la han llamado Berger y Luckmann-, que se ordena en función de esquemas significativos de experiencia que le otorgan sentido.

Tampoco podemos olvidar que la fenomenología de Schütz es un proyecto centrado en el sujeto, ya que este se encuentra implicado en la construcción misma de la realidad social: la dialéctica sujeto-sociedad es reflexiva, al contrario de la propuesta durkheimiana. El ser humano, en opinión del fenomenólogo, nace en el mundo social, vive su existencia cotidiana en él, y, sobre todo, lo experimenta como algo construido alrededor del lugar que ocupa. Abierto a su interpretación y acción, siempre está relacionado y hace referencia a su situación real biográficamente determinada (Schütz, 2003, p. 45). No olvidemos que el mundo de la vida cotidiana es real, como bien precisaron sus discípulos, Berger y Luckmann, en tanto se origina en los pensamientos y acciones de los miembros ordinarios de la sociedad y no puede existir si no es en la interactuación y comunicación continua con los otros. Pero es real desde una perspecti- va epistemológica dada y no como una realidad óntica.

La propuesta de Schütz (2003, p. 138) remarca que todas las relaciones que se dan en el contexto vital del individuo muestran las múltiples formas de comunicación entre los diferentes alter ego que contiene: los asociados (umwelt), contemporáneos (mitwelt), predecesores (vorwelt) —antepasados jamesianos- y sucesores (fogewelt). Estos no constituyen más que tipos o grupos de sujetos humanos con los que compartimos la historicidad de la cultura que encontramos en las tradiciones y las costumbres, en diversos grados de intimidad y anonimia. Precisamente, los medios de comunicación muestran modelos que permiten a los individuos y grupos adoptar formas de comportamiento social aceptadas o, incluso, crear en las realidades virtuales figuras que se adecúen a estos patrones ideales o aceptados por el grupo.

A este respecto, Berger y Luckmann proponen la noción teórica de universos simbólicos, entendida como marco legitimador del conocimiento general del mundo cotidiano que permite a los individuos ubicarse. Este concepto resulta de gran relevancia para comprender mejor el alcance subjetivo de los marcos de referencia en la construcción de las identidades, ya que pone de manifiesto que esta construcción es eminentemente simbólica $\mathrm{y}$, por tanto, carece de asiento o base esencializada, porque es ante todo me- 
diada (Sola, 2013). Además, carece de la ambigüedad o contradicción que, a juicio de algunos autores, reporta el de mundo de la vida (Blumenberg, 2013). Los universos simbólicos, para los autores, son «la matriz de todos los significados objetivados socialmente y subjetivamente reales; toda la sociedad histórica y la biografía de un individuo se ven como hechos que ocurren dentro de ese universo» (Berger \& Luckmann, 2008, p. 123). Inspirado en el mundo de la vida cotidiana de Schütz, este nuevo término incorpora la subjetividad como elemento de análisis central de la dialéctica de la realidad. Esta es propuesta aquí como un fenómeno que manifiesta el alcance de las significaciones construidas en la interacción intersubjetiva y que, por tanto, se encuentra en la base de la construcción dialéctica de las identidades. No olvidemos que son subjetividades, al fin y al cabo, las que construyen primero los relatos que circulan en los medios de comunicación, convertidos en saberes aceptados y discursos hegemónicos, pero también las que configuran día a día discursos alternativos en la realidad virtual (Sola, 2012). El encuentro aquí ya no tiene que ser cara a cara y puede ser mediado o virtual, y no por eso deja de ser el eje de la construcción de la realidad social. Además, tampoco podemos olvidar que estos universos (reales/virtuales) son productos sociales que tienen una historia y, por ello, están emplazados espacio-temporalmente.
Las identidades sociales vistas de este modo se conformarían gracias a la necesaria interrelación entre mundo social, subjetividad y universo simbólico, y dejarían de entenderse como algo problemático, puesto que las «áreas de conocimiento que de otra manera seguirían siendo reductos ininteligibles dentro de la realidad de la vida cotidiana, se ordenan así en una jerarquía de realidades, e ipso facto se vuelven inteligibles» (Berger \& Luckmann, 2008, p. 125). Esta jerarquía de realidades recuerda a la teoría de las realidades múltiples de Schütz, que se sustenta en la fenomenología de Edmund Husserl (mundo de la vida), el vitalismo de Henri Bergson (atención a la vida) y el pragmatismo de William James (subuniversos simbólicos). Y este orden permite reducir la complejidad, ubicar los acontecimientos colectivos y darles sentido y coherencia temporal incluyendo pasado, presente y futuro, matrices fundamentales en la construcción de la identidad social y constantemente presentes en el discurso de los medios. Con respecto al pasado, el universo simbólico «establece una 'memoria' que comparten todos los individuos socializados dentro de la colectividad. Con respecto al futuro, establece un marco de referencia común para la proyección de las acciones individuales» (Berger \& Luckmann, 2008, p. 131). Así, las narrativas mediáticas permiten a los miembros de la sociedad situarse en un horizonte significativo común que les conecta 
tanto con sus antecesores como con sus sucesores, mediante la memoria y la tradición, por una parte, y mediante las proyecciones futuras, entre las que, sin duda, se encuentran los productos de la cultura mediática y otras imaginerías culturales (Sola, 2012).

Pero ¿cómo pueden los individuos sentirse parte de un universo significativo instaurado por los medios? Partiendo de la internalización, es decir, de «la aprehensión o interpretación inmediata de un acontecimiento objetivo en cuanto expresa significado, o sea, en cuanto es una manifestación de los procesos subjetivos de otro que, en consecuencia, se vuelven subjetivamente significativos para mí» (Berger \& Luckmann, 2008, pp. 162-163). Este proceso permitirá, por tanto, comprender a los otros que nos rodean y aprehender el mundo social en cuanto realidad significativa ofrecida por el discurso mediático. La cuestión que se plantea entonces es ¿cómo se produce la internalización y qué relación tiene con la construcción de las identidades sociales? La respuesta es clara en este fragmento de Berger y Luckmann:

El niño se identifica con los otros significantes en una variedad de formas emocionales; pero sean estas cuales fueren, la internalización se produce solo cuando se produce la identificación. El niño acepta los «roles» y actitudes de los otros significantes, o sea que los internaliza y se apropia de ellos. Y por esta identificación con los otros significantes el niño se vuelve capaz de identificarse él mismo, de adquirir una identidad subjetivamente coherente y plausible (2008, p. 165).

Podría decirse, por tanto, que la internalización puede observarse en cualquier proceso posterior perteneciente a la socialización secundaria, siempre y cuando pertenezca a la identificación misma. Según Berger y Luckmann, las identificaciones se realizan dentro de horizontes que implican un mundo social específico, es decir, un marco de referencia dentro del cual los individuos logran estabilidad y continuidad en sus propias autoidentificaciones. A esto responde que para comprender la realidad social y psicológica que viven los sujetos es necesario considerar los marcos explicativos que dan cuenta de aquellas estructuras subyacentes que influyen en nuestra acción cotidiana, y es aquí donde los relatos mediáticos aparecen como una estructura fundamental de significado. No obstante, para profundizar en este proceso es preciso subrayar los aportes de la teoría del framing de Erving Goffman, que como veremos tiene sus orígenes en los aportes de los ya citados fenomenólogos, pero, a nuestro juicio, trasciende muchas de las dificultades planteadas y supera las limitaciones que hemos anunciado.

\section{Los marcos de la experiencia: la teoría del framing}

Los marcos, esquemas de referencia o frames son conceptos que han sido estudiados desde la psicología cogni- 
tiva, la fenomenología y la antropología, principalmente. A pesar de que el concepto de esquema fue inaugurado por el psicólogo Frederic Bartlett ${ }^{2}$, en 1932, no fue hasta los años setenta, con las propuestas de los psicólogos Marvin Minsky (1975), David E. Rumelhart y Donald A. Norman (1978), Roger Schank y Robert P. Abelson (1977), entre otros; o las de los antropólogos Gregory Bateson o Erving Goffman, sobre todo, cuando la noción se generalizó y alcanzó sistematicidad. En las últimas décadas este concepto sigue plenamente vigente y ha sido especialmente retomado desde los estudios de comunicación en relación, sobre todo, con el análisis de los efectos de los medios o la construcción social de la realidad (Carter, 2013; Dunn, 1977; Durham, 1998; Gamson et al., 1992; Hertog y McLeod, 2001; Iyengar, 1991; Reese et al., 2001; o Scheufele, 1999).

Aunque los distintos investigadores definen los esquemas en diferentes términos, no obstante, se puede apreciar una cierta consonancia fundamental desde el punto de vista teórico. Todos ellos, sean llamados esquemas, frames o guiones, son básicamente unidades de representación acerca de reglas, normas, símbolos o conceptos compartidos en una sociedad, que facilitan la interacción del sujeto con su contexto. Además, estos patrones organizados de pensamiento o esquemas simbólicos estructurados son esenciales para situarse y relacionarse en sociedad, ya que aportan una información esencial sobre las conductas apropiadas o las maneras de reaccionar ante una situación dada, información fundamental en los procesos de construcción de identidades sociales, como ya hemos anunciado.

Ahora bien, el alcance de la teoría del framing tiene su máximo exponente en la figura de Erving Goffman. Recordemos que su concepto de frame deriva del marco psicológico de Gregory Bateson (1977), que a su vez se basa en la distinción gestáltica fondo/figura; pero, además, Goffman la relaciona con el contexto, otorgándole así un carácter metacomunicativo (Lucerga, 2003). El término framing se puede traducir como enmarcar, situar en un marco o crear un marco de referencia y significa, propiamente, emplazar un hecho en un esquema determinado, permitiendo, de esta manera, desentrañar el sentido o los sentidos de un acontecimiento. Los marcos o esquemas interpretativos son aquellos elementos que convierten en algo con sentido lo que de otra manera sería un aspecto sin sentido de la escena de la vida cotidiana y nos permitirían responder a la sencilla pregunta: «¿Qué está pasando aquí?». Tal y como menciona Goffman

2 A pesar de las limitaciones de las primeras intuiciones de Bartlett, es importante destacar que el investigador trató de elucidar de qué forma se organizaba y construía la memoria acerca de un relato concreto en la mente de las personas, por ejemplo. 
(2006, p. 11), «marco es la palabra que uso para referirme a esos elementos básicos que soy capaz de identificar». $\mathrm{O}$, lo que es lo mismo, marcos serían aquellas definiciones de una situación, que se elaboran de acuerdo con los principios de organización y que gobiernan tanto los acontecimientos sociales como nuestra participación en ellos (Goffman, 2006, pp. 23-24).

En definitiva, estos esquemas permiten percibir, ubicar, reconocer $\mathrm{y}$ enmarcar una serie de sucesos y nos facilitan la comprensión general del funcionamiento del mundo y la reducción de su inherente complejidad. Esta comprensión del mundo es genérica, porque aunque el hombre trate de buscar explicación a todas las cuestiones que se plantea no la hallará siempre. Goffman señala, por ejemplo, entre otros muchos aspectos, la incidencia de lo asombroso en nuestra concepción del mundo. Como es sabido, en nuestra sociedad se acepta el importante supuesto de que todos los acontecimientos «reales» se pueden y deben incluir y manejar dentro del sistema convencional de creencias (que vendría a ser como el marco de comprensión habitual mundo de la vida de Schütz, o universo simbólico de Berger y Luckmann), pero no se acepta, formalmente, que haya hechos inexplicables que trasciendan el toldo de la ciencia o la supuesta normalidad.

Si observamos una situación o un individuo determinado y vemos que todo parece normal, es decir que las apariencias no provocan sospechas, podemos confirmar que el frame proyectado por ambos funciona naturalmente. De esta manera, la relación entre el sujeto y el marco está clara cuando el comportamiento del mismo resulta apropiado a su contexto, y será confusa cuando el comportamiento de los individuos no encaje en ninguno de los marcos esperados. Por ello, es importante señalar que estos esquemas, aunque varían en el grado de organización, aportan siempre elementos clave para la configuración de estructuras inestables, tales como la identidad social misma, que está siempre sujeta a cambios y contingencias. Algunos de los marcos son claramente presentables como un sistema de pautas que se repiten o son previsibles (normas sociales, por ejemplo, instauradas por instituciones como la familia, la escuela o los medios de comunicación); otros - la mayoría - parecen no tener una forma articulada evidente, y tan solo aportan comprensión, enfoque, perspectiva, o lo que es lo mismo, un cierto significado al acontecimiento observado. Es aquí donde la búsqueda de sentidos tiene que pasar por la indagación del marco de referencia donde el acontecimiento se instaura. Ya que, tal y como menciona Goffman, «cada clase de acontecimiento no es sino un elemento dentro de todo un lenguaje de acontecimientos, formando parte cada lenguaje de un marco de referencia distinto» (2006, p. 40).

Cuando observamos acciones que se encuentran totalmente enmarcadas 
en términos de un esquema primario, decimos que son reales o que suceden de hecho. Sin embargo, un cambio de clave nos aportaría algo que ya no ocurre literal o realmente, y que habríamos de interpretar. Por eso es tan importante tener siempre presente el contexto en el que se desempeñan los hechos observados. Como señala el autor, «en el mundo de la actividad real, cotidiana, el individuo puede predecir ciertos acontecimientos naturales con un aceptable grado de certe$\mathrm{za}$, pero los resultados interpersonales son necesariamente más problemáticos» (Goffman, 2006, p. 140). Es más, esto explicaría por qué la teoría del framing se encuentra tan relacionada con los procesos de configuración de las identidades. En la medida en que la construcción de la identidad es eminentemente interpretativa, los marcos resultan de gran utilidad para el análisis de las diversas interacciones. No podemos olvidar que todo encuentro social se produce en un contexto determinado que influirá notablemente en el comportamiento de los individuos participantes y que, por tanto, la identidad se construye de manera dialógica e interpretativa.

La interacción se convierte así en un fenómeno social clave para la construcción de las identidades sociales propias y ajenas. De este modo, cuando dos o más individuos se encuentran, construyen sus identidades o se identifican de cara a los otros, de modo que precisan de un marco desde el cual interpretar las acciones del otro y las suyas propias. Pero también cuando ocurre un encuentro en la recepción mediática o la participación virtual, se produce una ocasión de interacción, que implica y exige un trabajo de pacto, de colaboración y de disponibilidad de los participantes, aunque esta sea fingida o imaginada. De hecho, cada vez que estamos en presencia de otro, damos lugar a una serie de comportamientos o acciones que, en cierta medida -incluso más allá de nuestra conciencia-, están reglamentados, a fin de mantener la realidad social del tipo de encuentro que estamos manteniendo. Incluso cuando los individuos crean en el espacio virtual un second self, como diría Sherry Turkle (2005), este responde a unas pautas de comportamiento social instauradas por las instituciones socializadoras, entre las que se encuentran los medios. Aquí, los marcos generan expectativas y presuposiciones - sentido, al fin y al cabo- sin las cuales sería imposible interpretar la identidad propuesta o los rasgos de nuestra interacción. Para definir este tejido de análisis, el encuentro o desencuentro con el otro toma especial importancia en el entorno físico inmediato, es decir, en la interacción rutinaria, pero también en la interacción en la distancia, tal y como se produce en el espacio virtual, tan presente en la vida cotidiana hoy en día.

La creación de marcos de referencia se produce mediante sistemas de pensamiento que son fruto de la interacción simbólica, es decir, implican 
la interpretación recíproca y conjunta de los actos que se producen en sociedad, como diría Herbert Blumer (1982). Recordemos que, para este último, la interacción humana se ve mediatizada por el uso de símbolos, la interpretación o la comprensión del significado de las acciones del prójimo (1982, p. 60). Dicha concepción parte de la premisa de que todo esquema de sociedad humana está compuesto de personas involucradas en la acción y en la búsqueda de significación. Afirmación que respalda la visión dialéctica según la cual los medios construyen las identidades, pero, al mismo tiempo, estos relatos identitarios construidos por los individuos y los grupos influyen en las narrativas mediáticas sobre la identidad (Sola, 2012).

Al fin y al cabo, los marcos son estructuras epistemológicas que ordenan la acción colectiva y generan, a su vez, nuevos marcos que permiten explorar la puesta en escena - en palabras o en imágenes- en las que los individuos exponen y construyen sus identidades sociales. Así, la relación entre los marcos y las narrativas identitarias se puede considerar como de interdependencia. El hecho de que los individuos se sitúen en un marco desde el que interactúan y desde el que comprenden la realidad circundante evidencia que los procesos de construcción de identidades precisan ser interpretados, ya que varían según la situación. El alcance de la propuesta goffmaniana, por tanto, es fundamental. El análisis de la construcción del self no puede trascender, de ninguna manera, el contexto circundante. Es decir, el espacio y tiempo en el que las identidades (para los otros y para sí) son creadas e interpretadas. Como bien expuso Lupicinio Íñiguez, «no cabe análisis identitario alguno que pueda ignorar o ir más allá de las condiciones de posibilidad y el uso social de toda identidad» $(2002$, p. 218).

\section{Conclusiones}

Los aportes de la fenomenología y, sobre todo, las conclusiones obtenidas por Erving Goffman nos permiten tener una visión más completa acerca de las identidades. A la luz de esta perspectiva, las llamadas categorías de referencia, o exclusión por Tajfel, pasarían a convertirse en categorías temporales, de adscripción o proyección, siempre interpretables dentro de un marco cultural. Por ello, las identidades y su representación variarían en función de la situación y el contexto desde el cual el sujeto o el colectivo se instaura y, por tanto, deberían ser entendidas no como sustancias estancas o esencias, sino como procesos de construcción de significado en constante devenir y sujetos al cambio y las diversas situaciones comunicativas en las que los individuos se insertan.

Es preciso hacer constar también que, desde un marco determinado, una identidad social adquiere una serie de matices que pueden ser perfectamente aceptables para una cultura dada 
$y$, por el contrario, ser completamente incomprensibles para otra comunidad que se encuentra fuera del marco. Esto explica el a veces llamado «choque cultural» entre individuos, colectivos o naciones, y explicita las limitaciones del esencialismo. Pero no solo en el aspecto cultural la identidad social es constituida como una performance, sino también en el aspecto comunicativo. En función del frame comunicativo en el que un sujeto dado se encuentra con otros y teatraliza su identidad, podrán darse casos de diálogo o desencuentro. Por eso, la identidad solo adquiere sentido en la medida en que tiene lugar dentro de un marco de interacción coherente y comprensible para el resto de participantes, pero también siempre en relación con el sinsentido generado en los márgenes o fuera del marco de referencia. Aquí es donde los medios juegan un rol fundamental y no pueden ser obviados.

\section{Referencias}

Abrams, D., \& Hogg, M. A. (1990). Social Identification, Self Categorization and Social Influence. European Review of Social Psychology, 1 (1), 195-228.

Anderson, B. (1993). Comunidades imaginadas. Reflexiones sobre el origen y la difusión del nacionalismo. México: Fondo de Cultura Económica.

Bamberg, M. (2011). Who am I? Narration and its contribution to self and identity. Theory and Pshychology, 21 (1), febrero, 3-24.

Bandura, A. (2009). Social Cognitive Theory of Mass Communication. En J. Bryant, \& M. B. Oliver (Eds.), Media Effects. Advances in Theory and Research (pp. 94-124). Nueva York, NY: Routledge.

Bartlett, F. C. (1967). Remembering: A Study in Experimental and Social Psychology. Cambridge: Cambridge University Press.

Bateson, G. (1977). Steps to an Ecology of Mind. Nueva York, NY: Ballantine Books.

Bauman, Z. (2003). Modernidad líquida. Buenos Aires: Fondo de Cultura Económica.

Berger, P. L., \& Luckmann, T. (2008). La construcción social de la realidad. Buenos Aires: Amorrortu Editores.

Blumenberg, H. (2013). Teoría del mundo de la vida. México: Fondo de Cultura Económica.

Blumer, H. (1982). El interaccionismo simbólico: perspectiva y método. Barcelona: Editorial Hora.

Brown, R. (2000). Social Identity Theory: Past Achievements, Current Problems and Future Challenges. European Journal of Social Psychology, 30 (6), noviembre-diciembre, 745-778.

Bühler, P., \& y Habermacher, J. F. (1988). L'identité narrative. En La narration. Quand le récit devient communication (pp. 278-300). Ginebra: Les Editions Labor et Fides. 
Carter, M. J. (2013). The Hermeneutics of Frames and Framing: An Examination of the Media's Construction of Reality. Sage Open, abril-junio, $1-12$.

Dubar, C. (2002). La crisis de las identidades. Interpretación de una mutación. Barcelona: Ediciones Bellaterra.

Duch, L. (2010). Religió i comunicació. Barcelona: Fragmenta Editorial.

Dunn, M. G. (1977). Creating reality: How TV news distorts events? Contemporary Sociology, 6, 546-547.

Durham, F. D. (1998). News frames as social narratives: TWA Flight 800. Journal of Communication: Autumn, $48,100-117$.

Feilitzen, C. von \& Linné, O. (1975). Identifying with television characters. Journal of Communication, 25, 51-55.

Gamson, W. A., Croteau, D., Hoynes, W., \& Sasson, T. (1992). Media images and the social construction of reality. Annual Review of Sociology, 18, 373-393.

Goffman, E. (2006). Frame Analysis. Los marcos de la experiencia. Revista Española de Sociología, 8, 275277.

Hertog, J., \& McLeod, D. (2001). A Multiperspectival Approach to Framing Analysis: A Field Guide. En S. Reese, O. Gandy \& A. Grant (Eds.), Framing Public Life: Perspectives on Media and Our Understanding of the Social World. Mahwah, NJ: Lawrence Erlbaum.
Hogg, M. A., \& Hardie, E. A. (1992). Prototypicality, Conformity and Despersonalized Attraction: A SelfCategorization Analysis of Groups Cohesiveness. British Journal of Social Psychology, 31 (1), marzo, 41-46.

Husserl, E. (1991). La crisis de las ciencias europeas y la fenomenología trascendental. Barcelona: Editorial Crítica.

Íñiguez, L. (2002). Identidad: de lo personal a lo social. Un recorrido conceptual. En E. Crespo (Ed.), La constitución social de la subjetvividad (pp. 209-255). Madrid: Ediciones Catarata.

Iyengar, S. (1991). Is anyone responsible? Chicago, IL: University of Chicago Press.

James, W. (1989). Principios de psicología. México: Fondo de Cultura Económica.

Kerby, A. P. (1991). Narrative and the Self. Bloomington, IN: Indiana University Press.

Kintsch, W., \& Van Dijk, T. (1983). Strategies of Discourse Comprehension. Nueva York, NY: Academic Press.

Koselleck, R., \& Gadamer, H. G. (1997). Historia y hermenéutica. Barcelona: Paidós.

Lindgren, H. (1979). Introducción a la psicología social. México: Editorial Trillas.

Lucerga, M. J. (2003). Gregory Bateson: lectura en clave semiótica de una aventura epistemológica del siglo XX. Tonos, Revista Electrónica de Es- 
tudios Filológicos, 5. Recuperado de www.um.es/tonosdigital/znum5/ perfiles/bateson.htm

Merton, R. (1970). Teoría y estructura sociales. México: Fondo de Cultura Económica.

Minsky, M. (1975). A Framework for the Representation of Knowledge. En P. H. Winston (Ed.), The Psychology of Computer Vision (pp. 211-277). Nueva York, NY: McGraw-Hill.

Ovejero, A. (1997). El individuo en la masa: Psicología del comportamiento. Oviedo: Ediciones Nobel.

Pizzinato, A. (2008). Identidades contemporáneas: Ser a través de la historia y la palabra. Revista de Psicología Argumento, 26 (55), octubrediciembre, 349-355.

Reese, S. D., Gandy, O., \& Grant, A. (Eds.). (2001). Framing Public Life: Perspectives on Media and Our Understanding of the Social World. Mahwah, NJ: Lawrence Erlbaum.

Reicher, S. D. (1989). El comportamiento colectivo: Un estudio de campo. En J. F. Morales, \& C. Huici (Eds.), Lecturas de psicología social (pp. 173202). Madrid: Publicaciones de la UNED.

Ricoeur, P. (1996). Sí mismo como otro. Madrid: Siglo XXI Editores.

Ricoeur, P. (1999). Historia y narratividad. Buenos Aires: Paidós.

Ricoeur, P. (2007). Tiempo y narración. Configuración del tiempo en el relato histórico, vol. 1. Madrid: Siglo XXI Editores.
Rumelhart, D. E., \& Norman, D. A. (1978). Accretion, Tuning and Restructuring: Three Modes of Learning. En J. W. Cotton, \& R. Klatzky (Eds.), Semantic Factors in Cognition (pp. 37-54). Hillsdale, NJ: Lawrence Erlbaum Associates.

Schank, R., \& Abelson, R. (1977). Guiones, planes, metas y entendimiento. Barcelona: Paidós.

Scheufele, D. A. (1999). Framing as a theory of media effects. Journal of Communication, 48, 103-122.

Schrøder, K. C. (1994). Audience, Semiotics, Interpretive Communities and the Ethnographic Turn in Media Research. Media, Culture and Society, 16 (2), abril, 337-347.

Schütz, A. (1972). Fenomenología del mundo social. Psicología social y sociología. Buenos Aires: Paidós.

Schütz, A. (1972). La construcción significativa del mundo social. Buenos Aires: Paidós.

Schütz, A. (2003). El problema de la realidad social. Buenos Aires: Amorrortu Editores.

Schütz, A., \& Luckmann, T. (2001). Las estructuras del mundo de la vida. Buenos Aires: Amorrortu Editores.

Sherif, M. A. (1964). Reference groups: An exploration of conformity and deviance of adolescence and publishes attitudes and attitude change.

Sola Morales, S. (2012). La dialéctica entre las narrativas mediáticas identitarias y los procesos de identificación. 
Tesis doctoral. Departamento de Medios, Comunicación y Cultura. Bellaterra: Universidad Autónoma de Barcelona.

Sola Morales, S. (2013). Mediatic Narratives and Identification Processes. A theoretical and methodological approach. Revista Orbis, 24 (8), 36-50.

Somers, M. R. (1994). The Narrative Constitution of Identity: A Relational and Network Approach. Theory and Society, 23 (5), 605-649.

Stets, J. E., \& Burke, P. J. (2000). Identity Theory and Social Identity Theory. Social Psychology Quarterly, 63 (3), septiembre, 224-237.

Tajfel, H. (1984). Intergroup Relations, Social Myths and Social Justice in Social Psychology. En The Social Dimension, vol. 2 (pp. 695-715). Cambridge: Cambridge University Press.

Tajfel, H. (1996) [1984]. Grupos humanos y categorías sociales. Barcelona: Herder Editorial.
Taylor, C. (1996). Fuentes del yo. La construcción de la identidad moderna. Barcelona: Paidós.

Thiebaut, C. (1989). Sujeto complejo, identidad narrativa, modernidad del sur. En C. Castilla del Pino (Comp.), Teoría del personaje (pp. 121144). Madrid: Alianza Universidad.

Toledo, Ulises. (2007). Realidades múltiples y mundos sociales. Introducción a la socio-fenomenología. Cinta de Moebio. Revista de Epistemología de Ciencias Sociales, 30, diciembre, 211244. Recuperado de www.moebio. uchile.cl/30/toledo.html

Turkle, S. (2005). The Second Self: Computers and the Human Spirit. Cambridge, MA: MIT Press.

Turner, J. C. (1990). Redescubrir el grupo social. Madrid: Morata.

Turner, J. C. y Onorato, R. S. (1999). Social Identity, Personality and the Self-Concept: A Self Categorization Perspective. En T. R. Tyler et al. (Eds.), The Psychology of the Social Self (pp. 11-46). Mahwah, NJ: Lawrence Erlbaum Associates. 